\title{
Educação tecnológica e em valores na perspectiva de Viktor Frankl
}

\author{
Technological and value education in the perspective of Viktor E. Frankl \\ Educación tecnológica y en valores desde la perspectiva de Viktor Frankl
}

Flávio Luiz Honorato da Silva

ORCID: https://orcid.org/0000-0003-1307-3324

Universidade Federal da Paraíba, Brasil

E-mail: flavioluizh@yahoo.com.br

Maria Denise de Assis

ORCID: https://orcid.org/0000-0002-8290-3945

UNILIFE, Brasil

E-mail: mdeniseassis@gmail.com

Maria Clara Muniz Honorato

ORCID: https://orcid.org/0000-0002-2399-3354

Centro Universitário de João Pessoa, UNIPÊ, Brasil

E-mail: maria_claramh@hotmail.com

Alisson de Meneses Pontes

ORCID: https://orcid.org/0000-0003-1751-8394

UNILIFE, Brasil

E-mail: alissonedebora@hotmail.com

\begin{abstract}
Resumo
A Logoterapia e Análise Existencial é impactante na humanização da educação, pressuposto teórico do neuropsiquiatra Viktor Emil Frankl. A Logoterapia e Análise Existencial proposta teórico por Viktor Emil Frankl é impactante na humanização da educação, que pode ser mudada em ações para um estilo de vida na prática universitária de ensino, pesquisa e extensão que seja um modo de priorizar o ser sobre o ter (tecnológico, saber, as coisas), ser com os outros, ter empatia com o outro. A finalidade do artigo é utilizar os pressupostos teóricos da Logoterapia, apresentando caminhos que possam aprimorar a relação educador-educando que pode crescer no diálogo e mais engajamento na busca de humanização das relações dentro das instituições universitárias. O estudo de caso aqui apresentado é da área de tecnologia (engenharia, arquitetura, tecnologias), buscando modos de minimizar o vazio existencial de nossos alunos que tem como consequência aumento dos fenômenos de agressividade, criminalidade, dependência de drogas, depressão e chegando no limite do suicídio, que vem aumentando muito nos últimos anos.
\end{abstract}

Palavras-chave: Autotranscendência; Ensino superior; Ciência e tecnologia; Logoterapia.

\begin{abstract}
Existential Logotherapy and Analysis is impacting on the humanization of education, the theoretical assumption of psychoanalyst Viktor Emil Frankl. It is intended to present the importance of Frankl's thoughts in the humanization of technology education, which can be changed into actions for a lifestyle in university teaching, research and extension that is a way of prioritizing being over having ( technology, knowing things), being with others, empathizing with others. The purpose of the article is to use the theoretical assumptions of Logotherapy, presenting ways that can raise awareness of the educator-student relationship that can grow in dialogue and more engagement in the pursuit of humanization of relations within university institutions, especially in the case study here that is from the technology area (engineering, architecture, technologies), seeking ways to minimize the existential void of our students, which results in an increase in the phenomena of aggression, crime, drug addiction, depression and reaching the limit of suicide, which has been increasing greatly in the last years.
\end{abstract}

Keywords: Self-transcendence; University education; Science and technology; Logotherapy.

\section{Resumen}

La logoterapia y el análisis existencial inciden en la humanización de la educación, un supuesto teórico del neuropsiquiatra Viktor Emil Frankl. La Logoterapia y Análisis Existencial propuesto teóricamente por Viktor Emil Frankl tiene un impacto en la humanización de la educación, que se puede cambiar en acciones por un estilo de vida en la docencia universitaria, la investigación y la práctica de extensión que es una forma de priorizar el ser sobre el tener (tecnológico, saber, cosas), estar con los demás, empatizar con los demás. El propósito del artículo es utilizar los supuestos teóricos de la Logoterapia, presentando formas que pueden mejorar la relación educador-alumno que pueden crecer en el diálogo y más compromiso en la búsqueda de la humanización de las relaciones dentro de las instituciones universitarias. El caso de estudio que aquí se presenta es en el área de tecnología (ingeniería, arquitectura, tecnologías), buscando formas de minimizar el vacío existencial de nuestros estudiantes, lo que resulta en un aumento de los 
fenómenos de agresión, criminalidad, drogadicción, depresión y llegar al límite. suicidio, que ha ido aumentando mucho en los últimos años.

Palabras clave: Autotrascendencia; Enseñanza superior; Ciencia y tecnología; Logoterapia.

\section{Introdução}

Observa-se que o comportamento de professor (docente, educador) é impactante na formação dos nossos alunos (estudante, discente). Há uma placa em cima da mesa de trabalho na sala de um docente, que bem retrata isso, a frase: "professores ensinam, mas os melhores inspiram". É uma frase bem impactante, diante da responsabilidade da vocação de professor e de nosso caso de estudo o professor universitário. Na experiência de docente de parte dos autores, na maioria das vezes, o aluno não quer facilidades, nem burlar as normas da instituição, mas quer ser ouvido, buscando explicações para determinadas atitudes de colegas professores ou de atitudes da coordenação (graduação, pós-graduação) ou questionar certas atitudes dos superiores.

Também se verifica que, na maioria dos casos, o professor, das áreas mais tecnológicas, tem toda a boa vontade de ajudar o aluno em determinado momento difícil de sua trajetória. Mas, na maioria dos docentes, a falta de formação na área de relação humana e de entendimento das fases do aluno, induz a não perceber a pressão que é exercida, cobrando mais e mais deles para se tornar um profissional exemplar (é atitude do professor com as melhores intenções na trajetória acadêmica do aluno). Como o ser humano é único, cada um apresenta comportamento individual com relação às pressões normais da academia.

Em diversas vezes como professor de diversas disciplinas ou como coordenador de curso de graduação e de pósgraduação as reclamações dos estudantes são expostas afirmando que a academia (aí está implícito professor) deveria escutar e ajudar mais o aluno, para formar pessoa ou profissional consciente e responsável equilibrado (bom profissional na área e equilibrado psicologicamente), entretanto, muitas vezes, geram profissionais capacitados profissionalmente na tecnologia, mas doentes psiquicamente e frustrados como ser humano. Infelizmente isto é uma realidade em nossas instituições de ensino, verifica-se que é agravado pelo mundo virtual e impessoal da área tecnológica (modelagem, simulação, produtividade, resultados, ser o melhor, desempenho acima da média, estudar reduzindo o tempo de sono, entre outros). Insegurança e medo do presente, principalmente o futuro, são sentimentos presentes na vida de nossos alunos e se agrava mais com o decorrer do avanço do curso.

A finalidade do presente artigo não é responder a pergunta de como se resolve este problema (que é multifatorial), mas aguçar as nossas consciências (acreditamos) que com mais diálogo e mais engajamento na busca de humanização das relações dentro das instituições universitárias, principalmente, no estudo de caso aqui que é da área de tecnologia (engenharia, arquitetura, tecnologias), pode-se minimizar o vazio existencial de nossos alunos que tem como consequência aumento dos fenômenos de agressividade, criminalidade, dependência de drogas, depressão e chegando no limite do suicídio, que vem aumentando muito nos últimos anos.

A vida acadêmica dos alunos é uma parte de sua vida, tendo outros fatores psicossomáticos muitas influências na saúde psicológica do ser humano. Somos seres em desenvolvimento. O projeto de vida se conclui com o nosso fim aqui neste mundo (nossa finitude. Fim significa também meta).

Repetindo, que é lógico e óbvio que neste artigo não há pretensão de apresentar soluções ao problema do aumento de depressão, tentativa de suicídio (TS) e suicídio, mas uma busca de prevenção destes problemas, no contexto universitário, com a atuação mais humanizada de nossos educadores em relação aos educandos.

Com a apresentação teórica da Logoterapia e Análise Existencial como impactante na humanização da educação, pretendo mostrar que mesmo não sendo psicólogo, o educador da área tecnológica pode mudar suas ações para um estilo de vida na prática universitária de ensino, pesquisa e extensão que seja um modo de priorizar o ser sobre o ter (tecnológico, saber, as coisas), ser com os outros, ter empatia com o outro, para que possamos não ser um grupo, mas uma comunidade, onde se tenha mais satisfação no que se faz e por consequência um bem-estar psíquico-afetivo-emocional (Oliveira, 2018). 
Buscar, neste artigo, o conceito motivacional teórico da Logoterapia de Viktor Frankl para inferir na vida e aqui no caso da educação universitária tecnológica que é o conceito de "vontade de sentido" e a autrotranscendência da existência humana, onde a autrotranscendência é o caminho para algo ou para alguém além de si mesmo (não é ele mesmo) para um sentido que se deve cumprir (a uma causa, uma tarefa a ser cumprida, um amor a uma pessoa) que tem como consequência a realização do ser humano. O contrário deste caminho é a falta de sentido que gera no ser humano o vazio existencial. Em uma pesquisa com dependentes de droga entre jovens americanos, foi verificado que $100 \%$ dos casos o sentimento de vazio existencial é constatado (Frankl, 2015).

A contribuição da Logoterapia na educação em qualquer fase é de grande importância, em função do pensamento impactante da psicologia de Viktor Frankl como: "De um modo ou de outro: mais do que nunca a educação é, hoje em dia, uma educação para a responsabilidade. E ser responsável significa ser seletivo, ser meticuloso...devemos aprender a distinguir entre o que é essencial e o que não é, entre o que tem sentido e o que não tem, entre o que é responsável e o que não é...E assim como cada situação tem sua singularidade, de igual modo cada pessoa tem algo de singular...O sentido é, por conseguinte, o sentido concreto em uma situação concreta da vida" (Frankl, 2015).

Pode ser um sonho utópico, mas acreditamos no ser humano. Somos ser em desenvolvimento e assim ser de mudança. A frase chave da nossa esperança é que Viktor Frankl com autoridade de quem passou quase 4 anos em 4 campos de concentração na segunda guerra mundial e, graças à sua vontade de sentido, sobreviveu dizendo em bom tom que o ser humano procura realizações na sua vida que dão sentido à sua existência e este sentido é facilmente encontrado quando se vive a autotranscendência (saindo de se e indo ao outro na atitude da vida). Trabalho e amor são os caminhos que levam ao encontro do significado da vida em todos os seus momentos. Quando se falar de educação neste artigo não se está restrito a sala de aula, mas as várias tarefas como Empresa Junior-educação empreendedora, CA (centro acadêmico), Escola Piloto de Engenharia, ação voluntária, estágio, monitoria, comemoração (festa), participar de ONG entre outras tarefas. Quando se fala de professor (docente) gostamos mais de enfatizar a palavra educador (a). Quando se fala em comunidade, deve-se entender não um grupo reunido, mas ser com os outros (Pintos, 2017).

Lembrar que os filósofos Husserl e Stein acreditam na definição de comunidade como a organização que respeita a pessoa. Como exemplo, uma família estruturada é uma comunidade. Outra definição importante para o entendimento deste artigo é Ser-no-mundo. "Ser-no-mundo é a estrutura de transcendência, da ultrapassagem" (definição de Heidegger) (PIEPER, 2015). Autotranscendência para Frankl é "o ato do ser humano sempre apontar e se dirigir para algo ou alguém diferente de si mesmoseja um sentido a realizar ou outro ser humano a encontrar” (Frankl, 2015).

\section{Metodologia}

O artigo foi estruturado a partir de uma revisão da literatura apoiado na metodologia de Koche (2011), buscando informações de fundamentos da perspectivas da logoterapia que expande a compreensão do tema. Foram utilizados os fundamentos teóricos da Logoterapia e análise existencial de Frankl, dispondo da metodologia descritiva reflexiva, com fundamento fenomenológico-existencial na perspectiva dos pensamentos de Viktor Frankl mediante levantamento bibliográfico (Silva et al., 2020). O trabalho é constituído de caráter qualitativo, com uma visão do ser humano como um ser de possibilidades e de busca do sentido da vida, em qualquer momento. 


\section{Resultados e Discussão}

\section{Educação para a humanização (na esperança)}

No artigo filosofia existencial de Karl Jaspers, Perdigão (2001) afirma que Jaspers conceitua o ser-no-mundo (Dasein de Martin Heidegger) enquanto ser-em-situação, ou seja, situações que estão em volta da existência do ser humano, como liberdade, sofrimento, finitude, temporalidade, história da vida, transcendência.

O pensamento de Scheler é de vital importância na humanização da educação e outras áreas, pois seu objetivo principal em sua filosofia é recuperar o valor do ser humano, em função dele ser o valor principal, valor fonte ("o valor da pessoa é o valor dos valores") (Souza Neto, 2004). Para Scheler é preciso resgatar o valor e o valor bondade é a expressão mais verdadeira, real do amor ao outro. O valor amor para Scheler é comunicar-se que respeita as diferenças e nos vincula profundamente e sinceramente a uma amizade onde vai cada vez mais se aprofundando nesta amizade (Souza Neto, 2004). Na visão do filósofo Max Scheler, a educação apresenta como base o conceito principal de homem que na sua formação do "ser vir a ser" não deve ser limitada ao racional, mas deve ter o valor do amor (Shulz, 2017).

Para Scheler educação é humanização, sendo compreendida como projeto e processo (Shulz, 2017). A educação é um projeto/processo, em função do ser humano se tornar homem humanizado com centelha divina da dignidade. Nasce-se como projeto de existência, de vida. O educador (docente professor) deve ter como premissa que a sua função é despertar valores. Valores como respeito, a dignidade humana, a solidariedade, a empatia, a simpatia, a responsabilidade, entre outros. O cuidado com o outro é um paradigma que devemos, como educador, contribuir com a formação do discente (aluno), pois a relação docente-discente-comunidade (curso, sala de aula, coordenação de curso, departamento, centro, faculdade, universidade, Instituto Federal entre outras organizações-comunidades) é de vital importância que floresça a empatia (“... vivo o vivido dos outros como se fosse meu") (González, 1997). Vivenciar junto segundo Scheler é o que é denominado de simpatia (Alves et al., 2018).

A atual cultura contemporânea apresenta uma educação com pressão que gera educandos sem maturidade de pensar na sua individualidade, na sua subjetividade, mas empurra ao anonimato e ao coletivismo, ou seja, não sou eu mesmo, mas um ser a mais sem importância (Pintos, 2017).

A pessoa (o educador e o educando) é o centro de todo valor ético. É condição sine qua non que se assuma responsabilidade pelo outro, por ser "Ser" semelhante a mim ("Eu"). É preciso se buscar tempo para trabalhar valores como empatia, para ajudar a compreender as mazelas da atual sociedade de nossa comunidade universitária, principalmente a comunidade dos cursos de tecnologia (engenharia, arquitetura, tecnólogo, entre outros), que vive na cultura do positivismo, da pura razão, do objetivismo, da robotização dos sentimentos humanos, da violência, do abuso de drogas, do individualismo, com falta do amor ao próximo, da compaixão ("com-paixão").

O tempo que não se pode perder, pois é preciso aperfeiçoar a técnica, assim não tendo tempo para o encontro eu-tu para escutar as afecções do dia a dia do ser humano, seja a relação docente-docente (colegas), docente-discente (professor e aluno), docente-técnico administrativo, ou seja, encontro de pessoas que não são robôs, mas pessoa humana (ser humano) (Alves et al, 2018). O verdadeiro encontro é ver o ser singular que está na sua frente, escutar, discutir, tentar entender, "ser ouvidos".

Segundo o filósofo Buber não há relacionamento entre sujeito e objeto, mas sim a relação entre o eu e o tu, ou seja, uma relação sempre reciprocidade (Oliveira, 2017). Esta relação deve ser o centro de toda convivência entre partes da educação, que são docentes e discentes.

Scheler afirma que a humanização se faz com a elevação do espírito na abertura ao mundo (Scheler, 2012), ou seja, enquanto ser humano, a característica principal é a abertura ao mundo e ter consciência de si mesmo.

A humanização da comunidade acadêmica deve ter um pressuposto de vital importância que deverá ser uma a preocupação, principalmente, dos educadores (formadores de opinião) que o homem, a mulher de nosso tempo "não chegue a 
entender que de nada serve o desenvolvimento científico e tecnológico, se não produzir mais humanidade, e que é impossível construir uma paz autêntica sem bases sólidas da justiça e equidade" (Esclarín, 2006).

\section{Utopia na vida}

Utopia pode ser definida como o que vem a ser o que se imagina como sendo perfeito, ideal, mas imaginário, pois não se sabe, com alguma certeza, se é possível realizar o que é buscado.

Esclarín (2006) em seu livro "Educar para humanizar" afirma que nunca se deve perder o sonho, para não se conformar com as pequenas conquistas, claro que se deve dar valor, mas superar a tentação da rotina, da acomodação, da desesperança, da mediocridade. "Estamos num tempo em que o pessimismo com a política, o político, a autoridade constituída, virou moda, aumenta os coveiros da esperança. Utopia para enfrentar a crise da fé no homem, no transcendente. Crise de esperança, crise de compromisso com o outro. Utopia que se nega a aceitar que não são possíveis as transformações sociais e tecnológicas que melhoram a vida das pessoas, da cidade que moramos, do país que vivemos, do mundo que habitamos. Utopia que acredita na possibilidade de construir uma sociedade mais humana e um futuro digno para todos. Utopia que, por acreditar, se compromete na transformação da sociedade carcomida pela corrupção e a ganância de ter mais e esquece-se do próximo.”

Utopia para que a comunidade universitária do centro de tecnologia possa enfrentar novos desafios de justiça, igualdade, tolerância com o diferente. Utopia que vê a profissão que se busca alcançar, que se avizinha, ou se começa cursando, seja uma tarefa humanizada e humanizadora, capaz de transformar os mais insensíveis do ser humano, convidando para a fraternidade, a cooperação do serviço. Como preparar um mundo melhor, se você não acreditar nesta utopia? Você tem o direito de se sentir cansado e desanimado, mas não tem o direito de desistir nunca, nunca, nunca (Esclarín, 2006). "Neste mundo tão materialista, tão insensível e frio, que valoriza o ter, o possuir, o levar vantagem em tudo, esquecendo-se do outro" (Esclarín, 2006). Este mundo tem lugar para você que é idealista, que sonha, mas tem o pé no chão, vai atrás das conquistas. Este mundo tem espaço para Malala, Madre Tereza de Calcutá, Mandela, ...para você, sua mãe, seu pai, seu irmão, sua irmã, seu namorado, sua namorada, seu amigo, sua amiga, até seu inimigo, por que não?

Não renegue as utopias (ser humano. Aqui especificamos a comunidade acadêmica) e não deixe que asfixie sua esperança. Utopia que acredita que poderemos sonhar os melhores sonhos, como ambientes de trabalho que ocorra sempre o olhar nos olhos e sempre experimentar a alegria de trabalhar em grupo, ver no colega de trabalho um amigo e não um rival a ser derrotado. Sonhar sonhos possíveis cheios de sentidos, sendo lideres que formam pessoas autônomas e cidadãos responsáveis e fraternos (Esclarín, 2006).

Somos totalmente contrários à utopia da cultura do fácil, do não sofrer, como também do masoquismo (sofrer sem sentido, mas sim encontrar sentido ao sofrimento e as coisas difíceis). A utopia que falamos é a utopia que acredita na cultura do esforço e que o jovem deve-se preparar para aprender a lidar com o sofrimento, inerente a raça humana. Valorizar os dias de esforço no estudo de uma disciplina, da realização de um projeto, de uma avaliação (prova). Utopia que acredita no caminho certo de luta e esforço e não no jeitinho fácil como colar em avaliação, em um dado momento ter que perder a balada para estudar sozinho ou com os colegas. Utopia do crescimento, pois quem só quer caminhos fáceis, acaba com muita frequência, diante do sofrimento normal da vida como decepção com algo ou alguém, não aprovação em uma seleção de estágio ou emprego, procurar resolver a dor por intermédio de um caminho equivocado: drogas, violência com o outro. Utopia que acredita, como na escola da vida, onde os maduros (mais velhos) são os pós-doutorados nessa matéria, utopia do aprender sempre que devemos compartilhar alegrias, sofrimentos, prazeres e dores.

Mudar o jogo do mundo atual que afirma em voz alta: compro, logo existo. Levo vantagem, logo existo, por sonho, logo existo (Esclarín, 2006). Lembrar a frase: "Aquele que muda pode se equivocar; o que não muda vive se equivocando. O mundo mudará quando você mudar" (Esclarín, 2006), quando você acreditar que pode. 
Lembre-se que cada dia que se acorda é um dia para se viver, "hoje é o primeiro dia do resto de sua vida. O que você vai fazer desse resto, isso só depende de você, se irá preenchê-lo com tarefas que tenham sentido e até fazer dele talvez o período mais belo e fecundo de sua vida" (Lukas, 2005; Lukas, 2006).

Como utilizamos muito o conceito de variáveis na engenharia, considerando variável dependente a que é correlacionada a variável independente (que influencia-fator a variável dependente), pode-se fazer a analogia com o pensamento da Logoterapia e análise existencial, ou seja, o sentido existencial variável dependente pode ser correlacionado, na equação, com duas variáveis independentes, sendo as variáveis independentes as condições ou possibilidades de uma situação concreta e as capacidades (características e aptidões do ser humano na situação concreta da vida). As variáveis fatores influenciam a variável resposta (dependente) influenciando no sentido existencial da pessoa (Langle, 1992).

Pela maturidade da vida, os educadores podem apresentar a grande lição, nesse tempo que ainda pode-se acreditar e viver a utopia da mente clara, de colocar o otimismo pé no chão acima do pessimismo e não deixar que meu espírito não mais acredite na vida, no bem, na justiça, num mundo melhor, mas sempre vendo os outros, suas vidas, suas esperanças, seus esforços, seus planos para o futuro, isso hidrata qualquer tipo de ressecamento de minhas emoções.

Utopia que se fez carne e habitou esse mundo e sua mensagem vivida é revolucionária, muda o homem, torna-o humano, pois o gato não pode se "desgatizar", o cachorro não pode se "descachorar", mas o homem pode se desumanizar. "Tudo o que quereis que os homens vos façam, fazei-o vós a eles. Esta é a lei e os profetas” Jesus Cristo (Del Prette e Del Prette, 2011).

O caminho, numa graduação ou em qualquer especialização na vida, não é linear, mas em muitos momentos com trajetórias tortuosas e transtornos inerentes a caminhada. Olhar para trás e pensar que foi o melhor que tinha de ser feito, mas sempre aprendendo com os erros e descaminhos, buscando com as experiências vividas crescer como ser humano profissional, espiritual (cultural) e familiar (tripé do homem).

Viktor E. Frankl em sua sabedoria afirma: "Poderia dizer que só existo na medida em que existo para os outros. Podese dizer, ainda, que a felicidade é um subproduto de uma experiência de sentido da vida" (Frankl, 2015).

\section{A falta de percepção do sentido na vida e o sofrimento de viver (Logoterapia e Análise existencial de Viktor E. Frankl)}

Esta introdução não tem o objetivo de apresentar uma perspectiva teórica da Logoterapia e Análise Existencial de Viktor Emil Frankl, mas apresentar os principais pontos do seu pensamento para facilitar o entendimento do assunto do artigo. Há vários trabalhos que o leitor vai encontrar na literatura que apresentam bem a perspectiva teórica da Logoterapia (Frankl, 1992, Aquino, 2013, Xausa, 1986, Frankl, 2015).

Uma abordagem sobre Logoterapia (perspectiva teórica) não pode prescindir da figura humana de seu fundador o médico psiquiatra, neurologista e doutor em filosofia Viktor Emil Frankl, que nasceu em Viena em 1905 e faleceu na mesma cidade em 1997. A visão extraordinária dos pensamentos deste grande homem influenciou e influencia e deverá influenciar as gerações no tocante a filosofia, psicologia, sociologia, teologia, antropologia e como consequência na pedagogia educacional (Aquino, 2013).

Foi discípulo de Freud ( $1^{\mathrm{a}}$ escola da psicologia vienense) e depois de Adler ( $2^{\mathrm{a}}$ escola da psicologia vienense). Frankl sempre considerou a grande contribuição da psicanálise de Freud e os posicionamentos de Adler na psicologia individual, mas considerava que era necessário ultrapassar a visão psicológica do homem máquina para encontrar o Homo Humanus, ou seja, humanizar a psicologia, retirando o psicologismo (Frankl, 1992). Assim, gestou a Logoterapia, conhecida como $3^{\mathrm{a}}$ escola de psicologia vienense.

Ao falar sobre a humanização, a visão antropológica de Frankl, considera as dimensões psicofísicas, mas também a noológica (espiritual), como sendo a dimensão dos fenômenos especificamente humana, como o amor, a veneração, a ética e estética (FRANKL, 2015). 
Uma constatação muito importante para a vida do ser humano que Frankl observou é que a pessoa deve viver na sua liberdade e responsabilidade, não como o animal (que vive somente de instinto), ou viver o que os outros fazem, a moda do momento (conformismo), ou o que os outros querem que seja feito (totalitarismo) (Frankl, 2015).

Aureliano Pacciolla em seu ótimo livro Psicologia contemporâneo e Viktor Frankl: Fundamentos para uma psicoterapia existencial apresenta suscintamente 3 pontos importantes da Logoterapia (Pacciolla, 2015):

i) a vida da pessoa tem sempre um significado;

ii) a pessoa busca sempre um significado do seu ser, sua existência, que é conceituada por Frankl como valor da vontade de sentido;

iii) a pessoa apresenta potencialidade de experiência do sentido da vida em qualquer circunstância da vida.

Para Frankl é condição sine qua non que o ser eu significa ser consciente e é um ser livre e responsável (Aquino, 2013). Para Frankl a consciência é o órgão de significado do ser humano.

Segundo o filósofo da contemporaneidade, um escritor muito lido na atualidade, Byung-Chul Han, em seu livro Sociedade do cansaço um best seller, a sociedade do século XXI é uma sociedade de academias (fitness), muitos shopping centers para compras compulsivas. Sociedade do desempenho. Esta sociedade gera depressivos, Síndrome de Burnout (alma consumida), histéricos, nervosos e fracassados. O assédio moral por produtividade (considerado pandêmico), maior desempenho nos estudos e no trabalho (Han, 2017).

Como gerar algo de novo, novas descobertas científicas se o tempo é gasto apenas no desempenho, na produtividade, na quantidade, que só gera inquietações nos corações da juventude e nos educadores. Não há tempo de escutar o outro. De "ser ouvidos", de contemplar a natureza, de relaxar. Não há mais tempo de se espantar com o belo (natureza com o outro).

Onde anda o tempo para contemplação, para o ócio criativo? Nossa geração é imperativa e hiperneurótica (Han, 2017). Frankl afirma - o que é corroborado por Han - que o aceleramento de muitas atividades no dia a dia tem a ver com a carência do ser humano de ser.

O professor educador tem a missão (vocação), principalmente, neste tempo de sentimento de falta de sentido, que está na formação tecnológica (caso aqui em estudo) a formação de ser humano como cidadão ("ser-no-mundo"). Educar, ensinar, ser professor (docente) extrair do aluno o seu mais autêntico tesouro que é aprender, reaprender a aprender (educare, palavra latina que significa conduzir para fora, extrair, tirar de dentro, preparar o indivíduo para o mundo).

Ensinar a pedagogia de ver, de contemplar, de pensar (senso crítico). Ensinar que na vida da academia, do trabalho a experiência do ser com o outro nos faz experimentar o outro e ver como é gratificante trabalhar em conjunto. Pensar juntos, discutir e divergir enobrece o ser humano em todas as suas fases de vida. Esclarín (2006) afirma que toda autêntica vida do homem e da mulher é vida com os outros, é vida de convivência.

Este tempo que estamos vivendo século XXI, maximiza-se o viver individualista, discursos e práticas violentos, competitividade exacerbada (darwinismo social, ou seja, "sobrevivem somente os mais fortes, os que conseguem se adaptar às mudanças) (Esclarín, 2006). Assim, é confirmado que deve-se, com urgência urgentíssima, ensinar a nossa juventude que o trabalhar em grupo, em conjunto, é aprender a compartilhar buscando o bem comum (Esclarín, 2006).

Aprender a respeitar o diverso (religião, pensamento politico-claro não de visão fascista, raça, cultura, gênero), pois acrescenta a compreensão de ser mais tolerante (passar da tolerância para o verdadeiro respeito do diverso). O ser humano é, como afirma Frankl, um ser singular, único, na sua diversidade, uma unidade na diversidade (Frankl, 2015).

Como aprender a gestão de conflitos, se não respeitar o diferente. O conflito acrescenta ganhos na formação da juventude quando houver a compreensão que o conflito não é um mau em si mesmo, mas pensamentos diversos, interesses contrários que podem ser equacionados numa resolução que entra a negociação, a conversa, o respeito e principalmente a empatia. Gestão de conflitos é um aprendizado na convivência com o outro ("eu-outro"). 
Os valores da gestão de conflitos devem ser valores positivos, como afirma Scheler (2003) amor, empatia, respeito, humildade que tem como consequência resolução dos conflitos e gera paz, união da comunidade, uma convivência prazerosa. Mas se for usado o ódio e a violência para resolver conflitos à consequência é, por demais esperada, a divisão da comunidade e a separação de pessoas.

Os educadores precisam, por sua influência nos alunos, mostrar que conflito é salutar entre convivência e pode ser resolvido afirmando e vivendo no dia a dia da docência que a relação docente-discente e entre colegas (docente-docente e discente-discente) não deve ser uma relação de adversário, mas de colaboração. A atitude do professor não deve ser nem paternalista, nem assistencialista e nem impositiva.

A vocação central do professor educador é facilitar aos educandos a compreensão que o bem comum não deve ser edificado, mas ser permitido, ou seja, facilitar a compreensão do educando a importância da sua própria realização pessoal, tendo como efeito infalível o bem comum (Pintos 2017).

Frankl retira do pensamento de Goethe e organiza para compreensão de seu pensamento que se tomarmos o homem pura e simplesmente como ele é, vamos torná-lo, como aluno, (grifo nosso) pior, mas se tomá-lo como deve ele ser (projetoprojeção no futuro), vamos transformá-lo no que ele pode tornar-se (Frankl, 2015).

Uma pergunta para a docência da engenharia (neste estudo de caso): podemos facilitar o encontro de sentido na vida ao aluno de hoje, que na maioria, se sente existencialmente frustrado? Esta pergunta pode ser, também, para nós professores que se acham muitos, sem ver sentido na sua vocação de educador. Frankl questiona se a educação não está arrancando do ser humano de hoje o sentido da existência, em função de uma doutrinação reducionista (psicologismo, sociologismo, tecnicismo, fundamentalismo religioso e político, fanatismo) que desumaniza o homem. O sentido deveria ser factível?

Mas o sentido da vida não pode ser dado, o sentido tem que ser encontrado pelo homem vivente ("ser-no-mundo"). $\mathrm{O}$ sentido deve ser encontrado, mas nunca deve ser produto, ou seja, não pode ser produzido (Frankl, 2015). O sentido é uma fonte inesgotável e é onipresente. Não precisa, como as fontes energéticas, que pesquisa na Ciência e Tecnologia, se busca fontes alternativas (estudos na nossa área tecnológica), o sentido é o que o homem tem de mais humano e repito inesgotável e onipresente (Frankl, 2015).

É importante o educador situar o aluno, em qualquer fase do curso, de que a sua atitude diante da caminhada do curso deve ser uma atitude de protagonista de suas circunstâncias, descobrir a verdadeira liberdade que ele tem como "ser-no-mundo", e mostrar o equívoco que muitos tomam como seu a vitimização de suas circunstâncias e desiste de sua busca pelo sentido pela vida (Pintos, 2007).

Frankl associa a concepção niilista com o aumento do suicídio. Assim, é importante que nossa cultura acadêmica, principalmente na área tecnológica, que facilmente esquece que tudo que é feito na Ciência e Tecnologia tem como primazia o homem, a apresentação de que há sentido na vida e que este sentido deve ser buscado em cada momento de nossa existência, sendo conformado com cada momento desta existência. É preciso priorizar em nossas ações como educador o componente humanista, colocando no centro de toda ação o ser humano, mais que a tecnologia (Pacciolla, 2015).

O niilismo é um pensamento filosófico que preconiza que a existência da pessoa não tem sentido ou finalidade, desta forma não há um propósito para a existência humana. Este pensamento gera frustração existencial (como diz Frankl vazio existencial). O vazio existencial é percebido nos alunos pela sua apatia, pela falta de entusiasmo nas atividades acadêmicas (um tédio, angústia), não sentindo “sabor" em o que está realizando.

Pacciola (2014) utilizando a fundamentação logoterapêutica apresenta o ser humano orientado para um sentido de vida, onde ele é capacitado a decidir como guiar a sua vida para um determinado objetivo. Educar a pessoa formando para o sentido de liberdade-responsabilidade é conscientizar que esta pessoa pode buscar o sentido de sua vida em qualquer idade de sua vida e em qualquer circunstância. No trato com o outro (educando) é importante a sensação dele ser compreendido na sua demanda, 
mesmo que, muitas vezes, esta não seja concretizada, mas o processo de escutar e valorizar a sua demanda já responde uma inquietação da pessoa ouvida.

Claro que não é competência do professor da tecnologia realizar diagnóstico psicológico, pois não foi formado para esta função, mas com a sua experiência pode ser "ouvido" e em diálogo com o aluno mostrar a ele que ele precisa buscar um profissional da área. Atualmente na Universidade Federal da Paraíba é disposto aos alunos serviços de Clínica Escola de Psicologia, CRAS (Unidade do Centro de Referência de Atenção à Saúde) para os estudantes e toda sexta-feira, no Hospital Universitário Lauro Wanderley (HU), funciona o atendimento psiquiátrico voltado somente para estudantes da UFPB.

\section{Considerações Finais}

Retirado das contribuições do pensamento de Viktor Frankl, tentamos apresentar conclusões de ações importantes na mitigação dos problemas de relacionamento da comunidade acadêmica da tecnologia (docente-discente, discente-discente).

-Se o educador não for capaz, em seu ato de ensinar, gerar pessoas imunizadas contra o niilismo e o desespero, pelo menos não inocular neles este pensamento filosófico de falta de sentido.

-Se o educador tiver uma opinião de baixa consideração do aluno, gerando baixa estima, o educador torna pior o educando, mas se tiver uma opinião de boa consideração, gera alto estima, o educador está indicando ao aluno que ele pode chegar aonde ele tem condição de chegar (tornar-se naquilo que o educando pode vir a ser).

-Não a "busca da felicidade", mas entender que a felicidade é um produto da reação (aqui colocando palavras de nossa área tecnológica) de uma tarefa realizada (um trabalho bem concluído, uma ação voluntária, uma tarefa por uma causa, uma relação de amor com outra pessoa, uma produção artística...). Quanto mais se busca a felicidade, o prazer ou o poder, mais se afasta dele. Na Logoterapia esta prática é chamada de autotranscendência (lançar-se ao outro. Sair de si mesmo). Prática já confirmada na vivência psicológica.

-Não focar na autorrealização, considerando um objetivo de vida, pois não será atingido o objetivo, em função do que foi escrito acima, ou seja, como a felicidade, o prazer e tudo mais é uma consequência da autrotranscendência (não se preocupar, primeiramente, com si mesmo, mas com algo ou com outra pessoa, com uma tarefa com sentido a executar, um amor a viver bem).

-Buscar eliminar, nos atos da vida, ações de fanatismo, violência de qualquer motivo (político, de gênero, ambiental, cultural), morte física ou psíquica do outro (“A glória de Deus é o homem verdadeiramente vivo”- Santo Irineu). Não se deve falar de fanatismo religioso, porque o valor religioso abre a mente, enquanto o fanatismo é um fechar de mente (PINTOS, 2017).

-Aprender a buscar realizações na vida que concedam sentido à existência da pessoa.

-Saber prioritariamente que o ser humano tem liberdade de decisão e responsabilidade por esta decisão, não furtando desta responsabilidade em casos de erros.

-Lembrar que se a vida tem sentido, o sofrimento (pertencente ao viver do ser humano), também tem sentido. Não tem sentido sofrimento que pode ser mitigado como uma doença curável, um sofrimento de desrespeito por parte do outro para consigo. Se assim fosse é masoquismo querer sofrer.

-No ensino da tecnologia crescer na aprendizagem da sensibilidade com a coisa pública, com projetos com cunho de preocupação social e com o bem comum da coletividade.

-Sensibilidade com o meio ambiente, aprendendo a ter uma consciência que a nossa casa comum é a terra que habitamos.

-A vida questiona o ser humano e a resposta deste ser humano é avançar, buscando realizar na melhor versão o possível de si mesmo (Pintos, 2017). Fazendo analogia ao melhoramento dos programas computacionais, que a área da tecnologia usa em grande proporção para resolver problemas e agilizar tarefas do dia a dia do curso ou da profissão, o ser humano deve sempre está 
atualizando sua versão (versão 1.0, 2.0, 3.0 em diante). O melhoramento dos programas ganha versões atualizadas, fazendo deles um uso mais amigável e com mais janelas de resoluções.

-É o ser humano que com sua liberdade e responsabilidade decide quem quer ser e como alcançá-lo. É preciso sair da vitimização para protagonista de sua vida.

-Para conquistar algo, como uma conclusão de um curso é preciso um trabalho laborioso que é necessário, em boa parte do percurso, comprometer-se com a tarefa, esforço que será compensado.

-O viver com sentido ao longo do curso (realmente em todas as etapas da vida) é tempo de "ser com o outro", tempo dos "co" (colaborar, comunicar, conviver, cooperar, conceder corresponder etc.) (Pintos, 2017).

-Viktor Fankl alerta que o ser humano que vive a liberdade sem responsabilidade se torna opressor, por achar que viver livre é fazer tudo que tem vontade (como diz no jargão popular: "tudo que vem na telha"). Na verdade este ser humano está vivendo na escravidão das vontades.

-Não viver da impulsividade (cultura atual de viver o imediato), mas viver com prudência e tolerância, ou melhor, respeito.

Por fim, repetir o princípio da Logoterapia que "a busca por um sentido de vida é um fator primário, e mais ainda: a característica mais primária. E, se podemos chamá-la assim, um constitutivo da existência humana" (Frankl, 20015). Toda a visão de Frankl é libertadora, mas se esta ideia for transformada em vivência no ser humano, a educação tecnológica, no caso aqui referido, é humanizado e seremos educadores, educandos, comunidade acadêmica de Homo humanus.

\section{Contribuições para trabalhos futuros}

$\mathrm{O}$ tema em questão conduz ao desafio de uma busca incessante pela aprendizagem e o saber, pela forma que é guiada e transferida, onde o aprendiz é ao mesmo tempo educador e educando, esta troca incansável deverá ser portadora de muitos frutos, onde a tecnologia esteja a serviço de todos e não simplesmente de uma classe privilegiada. O que foi trabalhado neste artigo não se encerra aqui, ainda se faz necessário maior aprofundamento tanto na forma como o processo tecnológico avança como no aprofundamentos dos valores humanos, é possível desenvolver uma tecnologia onde o acesso não seja restrito para uma pequena classe. Aprofundar a relação educando, educador com possibilidades de respeito, crescimento, partilha, comprometimento, na busca da realização pessoal e da comunidade.

\section{Referências}

Alves, V. H., et al. (2018). Cuidado ético do outro: contribuições de Edith Stein e Max Scheler. Escola Anna Nery 22(2).

Aquino, T. A. A. (2013). Logoterapia e análise existencial: uma introdução ao pensamento de Viktor Frankl. Editora Paulus.

Del Prette, A.; Del Prette, Z. A. P. (2011). Habilidades Sociais - O modelo de Jesus. (2a ed.), Editora Vozes.

Esclarín, A. P. Educar para humanizar. (2006). Editora Paulinas.

Frankl, V. E. (1991). Em Busca de Sentido: um psicólogo no campo de concentração. Vozes.

Frankl, V. E. (2015). O sofrimento de uma vida sem sentido. Ed. É Realizações.

Frankl, V. E. (2019). A psicoterapia na prática. Vozes.

González, S. R. (1997). Crescer como pessoa: etapas e obstáculos. Editora Paulus.

Han, B-C. (2017). Sociedade do cansaço. (2a ed.). Editora Vozes.

Koche, J. C. (2011). Fundamentos de metodologia científica. Petrópolis: Vozes. http://www.brunovivas.com/wp-content/uploads/sites/10/2 018/07/K\%C3\%B6che-Jos\%C3\%A9-Carlos0D0AFundamentos-de-metodologia-cient\%C3\%ADfica-_teoria-da0D0Aci\%C3\%AAncia-e-

inicia\% $3 \% \mathrm{~A} 7 \% \mathrm{C} 3 \% \mathrm{~A} 3 \mathrm{o}-\% \mathrm{C} 3 \% \mathrm{~A} 0$-pesquisa.pdf

Langle, A. (1992). Viver com sentido. Editora Vozes. 
Research, Society and Development, v. 10, n. 1, e23910111690. 2021 (CC BY 4.0) | ISSN 2525-3409 | DOI: http://dx.doi.org/10.33448/rsd-v10i1.11690

Lukas, E. (2005). Histórias que curam...porque dão sentido à vida. Verus Editora.

Lukas, E. (2006). Psicologia EspiritualEditora Paulus, (2a ed.).

Oliveira, I. (2017). Vocação Dialógica Do Homem, Segundo Martin Buber. Psicologia.

Oliveira. N. R. (2018). Entre a pressa e a pausa: sentidos para o lazer e o ócio. Natal: Offser Editora.

Pacciolla, A. (2015). Psicologia contemporânea e Viktor Frankl: Fundamentos para uma psicoterapia existencial. Editora Cidade Nova.

Pieper, F.(2015). Filosofia e teologia em Heidegger. Notas sobre a conferência Fenomenologia e teologia de 1927. Numen: revista de estudos e pesquisa da religião, Juiz de Fora, 17(2), 9-134.

Pintos, C. G. (1999). A Logoterapia em contos: o livro como recurso terapêutico. (2a ed.), Editora Paulus.

Pintos, C. G. (2017). O mar me contou. A logoterapia aplicada ao dia a dia. Editora Cidade Nova.

Scheler, M. (2012). Da reviravolta dos valores. (2a ed.), Editora Vozes.

Scheler, M. (2003). A diferença essencial entre o homem e o animal. In: A posição do homem no cosmos. Editora Forense Universitária.

Shulz, A. (2017). Max Scheler: educar é humanizar. Espaço Pedagógico, Passo Fundo, 24(3), 552-564.

Silva, F. L. H.; Assis, M. D.; Durand, T. P.; Santos, E. N. M.; Honorato, M. C. M., \& Pontes, A. de M. Aging and meaning of life from the perspective of Viktor E. Frankl. Research, Society and Development, 9(11), e38591110068, 2020. 10.33448/rsd-v9i11.10068.

Souza Neto, C. C. (2004). Pessoa e os valores, aspectos do pensamento de Max Scheler, Revista Reflexão, 41-55.

Xausa, I. A. M. (1986). A psicologia do sentido da vida. (2a ed.), Editora Vozes Ltda. 